\title{
Evaluating Health-Related Quality of Life (HRQoL) in Iraqi Adult and Pediatric Patients with Beta-Thalassemia Major Using Two Different Iron Chelation Therapies
}

\author{
Ali J. Shawkat ${ }^{*}$, , Ahmed H. Jwaid**and Ghada M. Awad ${ }^{* * * *}$ \\ ** Department of Pharmacology, College of Pharmacy, University of Baghdad, Baghdad, Iraq. \\ ${ }^{* * *}$ AL-KaramaTeaching Hospital, Hereditary Blood Disorders Center, Baghdad, Iraq.
}

* * Ministry of Health and Environment, Baghdad, Iraq.

\section{Abstract}

Beta Thalassemia major $(\beta-\mathrm{TM})$ is a common inherited blood disorder in Iraq. Iron overload is caused by repeated blood transfusion; which may result in severe complications. Patients with $\beta$-TM require lifelong adherence to a burdensome medical regimen which could potentially impact their ' quality of life (QoL). Hence, it is of utmost importance to pay a great attention to their Health-Related Quality of Life (HRQoL).

A cross-sectional study was performed to evaluate health-related quality of life in both adult and pediatric patients using Deferoxamine (DFO) or Deferasirox (DFX) iron chelation therapies (ICTs) and to assess different factors affecting their elated quality of life.

Two instruments were used to evaluate quality of life; the WHOQOL-BREF questionnaire was used to evaluate quality of life in adults (DFO group and DFX group), and PedsQL was used to evaluate quality of life in pediatrics (DFO group and DFX group). Several variables were assessed for correlation with quality of life domains.

In adults patients; Health-Related Quality of Life (HRQoL) components were significantly lower in patients receiving Deferoxamine (DFO). In pediatric patients, only physical functioning score was significantly lower in Deferoxamine(DFO) receiving patients, the rest of the variables show no statistical differences. Pediatrics have slightly better quality of life $(\mathrm{QoL})$ and lower complications in comparison to adults.

Thalassemia impairs quality of life $(\mathrm{QoL})$ in all patients significantly. Improving quality of life (QoL) is achieved by better control of iron overload, iron chelation therapies (ICTs) adverse effects, and complications. Keywords: beta-thalassemia major, QoL, PedsQL, WHOQOL-BREF

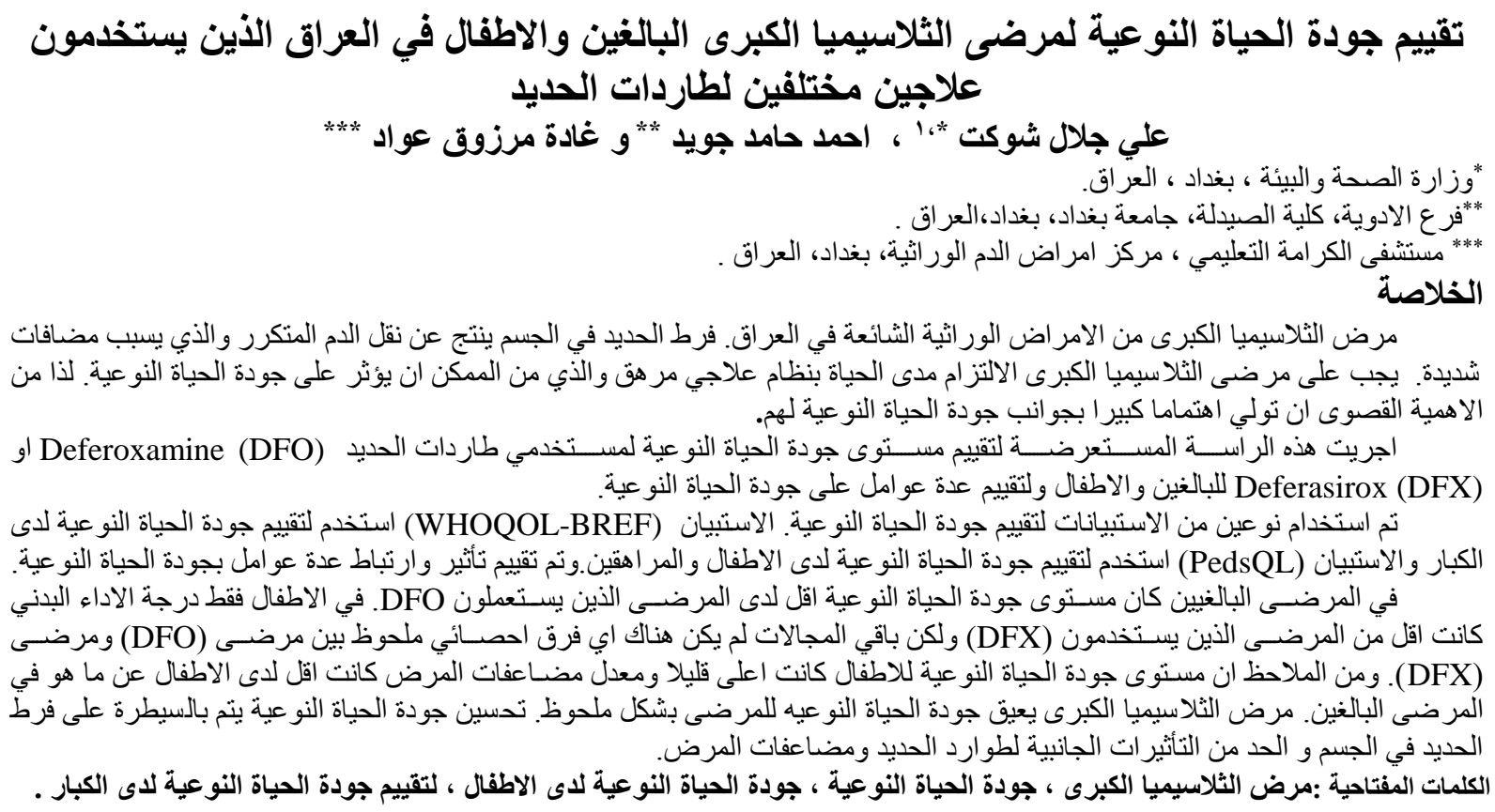

${ }^{1}$ Corresponding author: E-mail: alijalal0135@gmail.com

Received: $28 / 8 / 2018$

Accepted: $6 / 11 / 2018$

Iraqi Journal of Pharmaceutical Sciences 


\section{Introduction}

Beta thalassemia syndrome is a group of hereditary blood disorders that are mainly characterized by reduction or absence of $\beta$-globin chain synthesis, resulting in a reduction of hemoglobin in red blood cells (RBCs), decreased production of RBCs and consequently anemia ${ }^{(1,2)}$. Thalassemia disease was first described by Thomas B. Cooley and pearl Lee in $1925^{(2,3)}$. In Iraq, there is a high prevalence of $\beta$-TM. The prevalence rate in 2015 was 27.4 per 100,000 population ${ }^{(4)}$. The $\beta$ globin synthesis is normally regulated by two $\beta$ genes; one on each copy of chromosome $11^{(5)}$. Thalassemia is an autosomal recessive genetic condition, caused by point mutation within or near $\beta$-gene. Such mutations result in either absence of the $\beta$ gene $\left(\beta^{0}\right.$-thalassemia) or reduction in synthesis of the $\beta$ gene $\left(\beta^{+} \text {-thalassemia }\right)^{(6)}$. The reduction or absence of the $\beta$-globin chains results in a relative excess of $\alpha$-globin chains, which when unpaired are unstable and precipitate in the erythroid precursors in the bone marrow, consequently there is ineffective erythropoiesis and the mature cells that reach the circulation have a shortened lifespan ${ }^{(7)}$. The cornerstone management for patients with $\beta$-TM is based on lifelong transfusion and iron chelation. The aims of transfusion are to correct anemia, suppress ineffective erythropoiesis (8). Without iron chelation therapy (ICT) the regular blood transfusion would increase the iron stores to several times the normal levels, iron overload results in severe complications including cardiac disease, osteopathy and endocrine complications $^{(9,10)}$.

Deferoxamine (DFO) was the first invented ICT, before its invention chronically transfused thalassemia patients were dying from cardiac iron overload in their twenties; but the life expectancy has improved since after ${ }^{(9)}$. DFO is given as subcutaneous infusion for 8 hrs per day, 5 days per week. DFO has a negative impact on thalassemia patients' quality of life (QOL) as the infusions can be very troublesome, painful and time consuming with restrictive activity ${ }^{(9,10)}$. Compliance with DFO and its rigorous requirements of daily subcutaneous infusion still a limiting factor for treatment success. DFO chelates iron only during the time infused, hence, poor compliance with DFO results in gaps in chelation coverage $^{(11)}$.Deferasirox (DFX) is the most recent oral chelator ${ }^{(9)}$. DFX has a half-life of 11-19 hrs. allowing for once-daily oral dosing ${ }^{(12)}$. Treatment with DFX is beneficial due to dramatically improved compliance which was reported to be $>80 \%$; in which DFX is more satisfying and found to be more convenient than DFO as it comprises a reduction in dosing frequency ${ }^{(9,11)}$. ICTs may complicate patients' QoL due to their serious side effects ${ }^{(13)}$.
The World Health Organization (WHO) defines quality of life as: "An individual perception of their position in life in the context of the culture and value systems in which they live and in relation to their goals, expectations, standards, and concerns" (14). Health related quality of life (HRQOL) is visualized as the patients' perception of the impact of the disease and treatment on their physical, psychological, social functioning and well-being ${ }^{(15)}$. Patients with $\beta$-TMare suffering from disease chronicity including frequent hospitalization, blood dependence, continuous treatment with ICT; physical health limitations as growth retardation, poor physical appearance, and delayed puberty, in addition to disease complications. This imposes a requirement to make regular follow-up and medical care monitoring for physical, psychological, social aspects of patients with $\beta$-TM to help them cope with their illness to live as normal life as possible ${ }^{(16)}$. Assessing QoL in this population provides a better understanding of the disease burden that the patient experiences every day, to measure the impact of the treatment and how does the patient go along with it, and to predict outcomes such as mortality and morbidity ${ }^{(17)}$.

\section{Patients and methods}

\section{Patient selection and study design}

The present study was designed as a singlecenter, cross-sectional study. The study was performed at AL-Karama teaching hospital/ department of hereditary blood disorders (thalassemia center). The participant, patients, in this study were all with $\beta$-TM trait who were attending thalassemia center at AL-karama hospital for recurrent blood transfusion and for receiving their iron chelation therapy. A total of 201 patients approved to be enrolled in the study. The patients were divided into two main groups: Group A: patients on deferoxamine (DFO) were sub-divided into two groups: children and adolescents (8-18 years) and adults (19 and more). And; Group B: patients on deferasirox (DFX) were sub-divided into two groups: children and adolescents (8-18 years) and adults (19 and older).

The sample size was calculated by using Raosoft sample calculator (online tool). A total of 600 patients with $\beta$-TM were registered at ALKarama thalassemia center, hence; a sample size of approximately 200 patients should be included, assuming a margin of error of $5 \%$ and a confidence level of $95 \%$.

\section{Method of quality of life assessment}

Adults (19 years and older) HRQoL were assessed by The World Health Organization Quality Of Life (WHOQOL-BREF) questionnaire which is validated for QoL assessment in $\beta-\mathrm{TM}^{(18)}$. Ethical approval for the use of the questionnaire was obtained from the $\mathrm{WHO} /$ information, evidence and research department. WHOQOL- 
BREF questionnaire comprises 26 questions; Two questions are concerned with the patient's overallperceptions of the QoL, and the patient's overall perception on health, the remaining 24 questions are assessing 4 domains namely: physical health (domain 1) (7 questions), psychological (domain 2) (6 questions), social (domain 3) (3 questions) and environmental (domain 4) (8 questions). The answers were dependent on the patient's health status over the past 2 weeks. The patients' responses were rated on a 5-points Likert scale ${ }^{(19,20)}$. Then the four domains were calculated, and the obtained raw scores were transformed to the 4-20 scale and their corresponding 0-100 scale according to the manual of the questionnaire ${ }^{(21)}$. The Arabic version of WHOQOL-BREF is valid an reliable to be used in assessing HRQoL in Arab populations ${ }^{(18)}$. HRQoL was assessed in children (8-12 years) and adolescents (13-18 years) by using PedsQL ${ }^{\mathrm{TM}_{4}} 4.0$ questionnaire which was formulated by Varni and colleagues $^{(22)}$. Ethical approval and agreement for using the questionnaire were obtained.The Arabic version of the PedsQL ${ }^{\mathrm{TM}} 4.0$ questionnaire is a 23 question instrument considered to be feasible, reliable and valid to assess QoL in Iraq ${ }^{(23)}$. The questionnaire includes 4 domains: physical functioning (8 questions), emotional functioning (5 questions), social functioning (5 questions); school functioning (5 questions) ${ }^{(15)}$. The patients' answers were represented on a 5-points Likert scale for each question. The mean score was computed by the sum of the questions' scores over the number of the questions answered. PedsQL ${ }^{\mathrm{TM}} 4.0$ has additional advantage of evaluating psychosocial health summary score (the sum of the questions' score over the number of the questions answered in the emotional, social and school functioning scales), physical health summary score (physical functioning scale score) and total summary score (sum of all questions' over the number of questions answered on all the scales) ${ }^{(14,22)}$. The PedsQL ${ }^{\mathrm{TM}} 4.0$ scores range from 0-100 points with higher scores indicating better HRQoL ${ }^{(14)}$.

\section{Statistical analysis}

Anderson Darling test was done to assess whether continuous variables follow a normal distribution. If the variables were following normal distribution, then mean and standard deviation were used, and if they did not follow normal distribution then median and interquartile range (25\%-75\% percentile range) were used to present the data. Discrete variables presented using their numbers and percentages, Chi square test was used to analyze the discrete variables (or Fisher exact test when Chi square test is not valid; due to low sample size $<20$ and if 2 or more with an expected frequency is less than 5). Two samples t-test was used to analyze the differences in means between two groups (if both follow a normal distribution with no significant outlier).

Binary logistic regression analysis was used to calculate the odd ratio (OR) and their 95\% confidence intervals $(\mathrm{CI})$, when the outcome can be categorized into 2 binary levels, and if appropriate probability plot used to present the relationship.

Linear regression analysis was performed to assess the relationship between different variables. If one or both of the variables were following a normal distribution, person correlation was used. If both did not follow a normal distribution, spearman correlation was used. Scatter plot was used to present the regression analysis. Correlation coefficient or standardized beta (r) is a representative of magnitude and direction of the relationship; $0.00-0.29=$ little or no correlation; 0.3$.49=$ weak; $0.5-0.69=$ moderate; $0.7-0.89=$ strong; and $0.9-1.00=$ very strong. A negative sign indicates an inverse relationship, while a positive sign indicates a direct relationship. SPSS 22 (Chicago, IL), Minitab 17.1.0 software package was used to make the statistical analysis, $\mathrm{p}$ value considered to be significant if less than 0.05 .

\section{Results}

Demographic data and disease characteristics

A total of 201 patients were approved to be included in the study. Table (1) demonstrates patients included in the study as three groups (children (8-12), $\mathrm{n}=40$; (19.9\%)), (adolescents (1318), $n=78 ;(38.8 \%)$ ), and (adults $(>19), n=83$; $(41.3 \%)$ ), but; children and adolescents were considered as one category (pediatric) during the study. The demographic data and social characteristics were demonstrated in table (1) 
Table (1) Demographic data and disease characteristics

\begin{tabular}{|c|c|}
\hline Variables & Value \\
\hline Number & 201 \\
\hline Age (years), mean \pm SD & $19.1 \pm 7.3$ \\
\hline 8-12 years & $40(19.9 \%)$ \\
\hline 13-18 years & $78(38.8 \%)$ \\
\hline$\geq 19$ years & $83(41.3 \%)$ \\
\hline \multicolumn{2}{|l|}{ Gender } \\
\hline Female & $107(53.2 \%)$ \\
\hline Male & $94(46.8 \%)$ \\
\hline BMI $\left(\mathrm{kg} / \mathrm{m}^{2}\right)$, mean \pm SD & $21.4 \pm 4.0$ \\
\hline Frequency of attendance (days), mean \pm SD & $14.7 \pm 4.3$ \\
\hline Age at which disease was diagnosed (months), mean \pm SD & $13.7 \pm 9.0$ \\
\hline Married (consanguineous) $($ adults $=101)$ & $12,(11.9 \%)$ \\
\hline \multicolumn{2}{|l|}{ Education level (patients) } \\
\hline Illiterate & $40,(19.9 \%)$ \\
\hline Non-college & $133,(66.2 \%)$ \\
\hline College & $28,(13.9 \%)$ \\
\hline \multicolumn{2}{|l|}{ Education level (father) } \\
\hline Illiterate & $54,(26.9 \%)$ \\
\hline Non-college & $97,(48.3 \%)$ \\
\hline College & $50,(24.9 \%)$ \\
\hline \multicolumn{2}{|l|}{ Education level (mother) } \\
\hline Illiterate & $122,(55.7 \%)$ \\
\hline Non-college & $76,(37.8 \%)$ \\
\hline College & $13,(6.5 \%)$ \\
\hline
\end{tabular}

SD (standard deviation)

BMI (body mass index)

\section{Associated disease complications}

The frequency of hepato-splenomegaly, viral hepatitis, thalassemic facies and splenectomy are significantly higher in adults compared to pediatric patients, as illustrated in table (2). Figure (1) shows the percentages of complications in all patients.

Table (2) Thalassemia associated complications

\begin{tabular}{||l|l|l|l||}
\hline Variables & Pediatrics $^{*}$ & Adults & $\begin{array}{l}\text { p- } \\
\text { value }\end{array}$ \\
\hline Number & 100 & 101 & - \\
\hline $\begin{array}{l}\text { Hepato- } \\
\text { splenomegaly }\end{array}$ & $41,(41 \%)$ & $\begin{array}{c}59, \\
(58.4 \%)\end{array}$ & 0.014 \\
\hline DM & $4,(4 \%)$ & $\begin{array}{c}7, \\
(6.9 \%)\end{array}$ & 0.361 \\
\hline Hypogonadism & $11,(11 \%)$ & $\begin{array}{c}20, \\
(19.8 \%)\end{array}$ & 0.084 \\
\hline $\begin{array}{l}\text { Cardiac } \\
\text { involvement }\end{array}$ & $21,21 \%)$ & $\begin{array}{c}31, \\
(30.7 \%)\end{array}$ & 0.117 \\
\hline Viral hepatitis & $23,(23 \%)$ & $\begin{array}{c}65, \\
(64.4 \%)\end{array}$ & $<0.001$ \\
\hline $\begin{array}{l}\text { Thalassemic } \\
\text { facies }\end{array}$ & $60,(60 \%)$ & $\begin{array}{c}78, \\
(77.2 \%)\end{array}$ & 0.008 \\
\hline cholecystectomy & $9,(9 \%)$ & $\begin{array}{c}5, \\
(4.9 \%)\end{array}$ & 0.215 \\
\hline Splenectomy & $8,(8 \%)$ & $\begin{array}{c}31, \\
(30.7 \%)\end{array}$ & $<0.001$ \\
\hline
\end{tabular}

*Pediatric (children and adolescents)

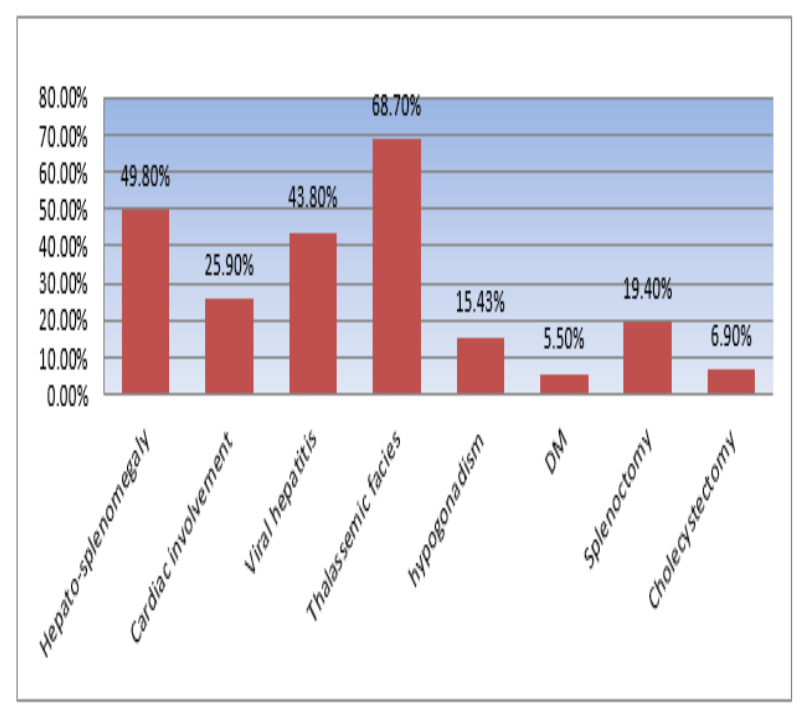

Figure (1) percentages of complications in thalassemia major patients.

\section{Reported side effects with ICTs usage}

Side effects were reported according to BNF 74, and drugs monograms (Novartis), side effects associated with impaired QoL in thalassemia patients. Fatigue was significantly higher in pediatrics $(\mathrm{P}<0.05)$; urinary discoloration and permanent skin reaction were significantly higher in adults $(\mathrm{P}<0.05)$, as illustrated in table (3). 
Table (3) Reported side effects with ICTs .

\begin{tabular}{|c|c|c|c|}
\hline Variables & Pediatrics" & Adults & $\begin{array}{l}\text { p- } \\
\text { value }\end{array}$ \\
\hline Number & 100 & 101 & 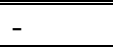 \\
\hline $\begin{array}{l}\text { GIT } \\
\text { disturbances } \\
\text { (DFX) }\end{array}$ & $43,(43 \%)$ & $\begin{array}{l}55, \\
(54.5 \%)\end{array}$ & "0.104 \\
\hline $\begin{array}{l}\text { Urine } \\
\text { discoloration } \\
\text { (DFO) } \\
\end{array}$ & "48, (48\%) & $\begin{array}{l}93, \\
(92.1 \%)\end{array}$ & $\bar{c}_{<0.001}$ \\
\hline Fatigue & $25,(25 \%)$ & $\begin{array}{l}10, \\
(9.9 \%)\end{array}$ & 0.005 \\
\hline Joints pain & $23,(23 \%)$ & $\begin{array}{l}33, \\
(32.7 \%)\end{array}$ & 0.126 \\
\hline $\begin{array}{l}\text { Skin } \\
\text { reactions } \\
(\text { DFO) } \\
\end{array}$ & $7,(7 \%)$ & $\begin{array}{l}20, \\
(19.8 \%)\end{array}$ & 0.008 \\
\hline Pyrexia & $21,(21 \%)$ & $\begin{array}{l}18, \\
(17.8 \%)\end{array}$ & 0.569 \\
\hline $\begin{array}{l}\text { Sleep } \\
\text { disturbance } \\
\text { (DFO) }\end{array}$ & $15,(15 \%)$ & $\begin{array}{l}26, \\
(25.7 \%)\end{array}$ & 0.059 \\
\hline $\begin{array}{l}\text { Stool } \\
\text { discoloration } \\
\text { (DFX) }\end{array}$ & $33,(33 \%)$ & $\begin{array}{l}32, \\
(31.7 \%)\end{array}$ & 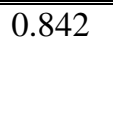 \\
\hline
\end{tabular}

Assessment of HRQoL by WHOQOL-BREF questionnaire in adult patients using either DFO or DFX chelation therapy.
In adults patients; HRQoL components were significantly lower in patients receiving DFO, as illustrated in table (4).

Table (4) Assessing HRQoL in adults using DFO or DFX by WHOQOL-BREF questionnaire.

\begin{tabular}{||l|l|l|l||}
\hline Variables & $\begin{array}{l}\text { Defero- } \\
\text { xamine }\end{array}$ & $\begin{array}{l}\text { Defera- } \\
\text { sirox }\end{array}$ & $\begin{array}{l}\text { p- } \\
\text { value }\end{array}$ \\
\hline & & & \\
\hline Number & 51 & 50 & - \\
\hline Physical health & 48.9 & 63.9 & $<\mathbf{0 . 0 0 1}$ \\
& \pm 14.7 & \pm 18.0 & \\
\hline Psychological & 47.1 & 65.9 & $<\mathbf{0 . 0 0 1}$ \\
& \pm 19.4 & \pm 16.2 & \\
\hline Social & 63.6 & 74.2 & $\mathbf{0 . 0 1 6}$ \\
relationship & \pm 22.8 & \pm 20.8 & \\
\hline Environmental & 40.6 & 58.3 & $<\mathbf{0 . 0 0 1}$ \\
& \pm 16.6 & \pm 22.1 & \\
\hline
\end{tabular}

Predictors of QoL for adult patients

Age, blood transfusion frequency, and splenectomy were found to have no impact on QoL. DFX has a strong significant correlation with QoL domains. Educational level poses a significant correlation with QoL domains. Thalassemic facies have a negative impact on QoL domains. Serum ferritin was negatively correlated with psychological and environmental domains and marginally correlated with physical functioning domain, as illustrated in table (5).

Table (5) Predictors of QoL in adult patients

\begin{tabular}{|c|c|c|c|c|c|c|c|c|}
\hline & \multicolumn{2}{|c|}{ Physical Health } & \multicolumn{2}{|c|}{ Psychological } & \multicolumn{2}{|c|}{$\begin{array}{l}\text { Social } \\
\text { relationship }\end{array}$} & \multicolumn{2}{|c|}{ Environmental } \\
\hline & $\mathbf{r}$ & p-value & $\mathbf{r}$ & p-value & $\mathbf{r}$ & $\begin{array}{l}\text { p- } \\
\text { value }\end{array}$ & $\mathbf{r}$ & p-value \\
\hline Age & -0.092 & 0.359 & -0.081 & 0.423 & -0.139 & 0.164 & -0.090 & 0.372 \\
\hline $\begin{array}{l}\text { Treatment } \\
\text { (DFX) }\end{array}$ & 0.431 & $<0.001[\mathrm{~S}]$. & 0.473 & $<0.001[\mathrm{~S}]$. & 0.244 & $\begin{array}{l}0.014 \\
{[\text { S.] }}\end{array}$ & 0.398 & $<0.001[\mathrm{~S}$. \\
\hline Education level & 0.260 & $0.009[\mathrm{~S}]$. & 0.289 & $0.003[\mathrm{~S}]$. & 0.236 & $\begin{array}{l}0.017 \\
{[S .]}\end{array}$ & $\begin{array}{l}0.207 \\
{[S .]} \\
\end{array}$ & $0.038[\mathrm{~S}]$. \\
\hline $\begin{array}{l}\text { Attendance } \\
\text { frequency }\end{array}$ & -0.093 & 0.355 & -0.054 & 0.290 & -0.025 & 0.807 & -0.037 & 0.711 \\
\hline $\begin{array}{l}\text { Thalassemic } \\
\text { facies }\end{array}$ & -0.239 & 0.016 [S.] & -0.329 & $0.001[\mathrm{~S}]$. & -0.156 & 0.120 & -0.245 & 0.014 [S.] \\
\hline Splenectomy & 0.004 & 0.968 & 0.011 & 0.912 & -0.036 & 0.722 & 0.007 & 0.944 \\
\hline Ferritin & -0.184 & 0.065 & -0.284 & 0.004 [S.] & -0.136 & 0.176 & -0.200 & $0.045[\mathrm{~S}]$. \\
\hline
\end{tabular}

\section{Assessment of HRQoL by PedsQL questionnaire in} pediatrics using either DFO or DFX chelation therapy.

In pediatric patients, only physical functioning score was significantly lower in DFO receiving patients, the rest of the variables show no statistical differences, as illustrated in table (6). The emotional functioning was the lowest scored domain in both groups. 
Table (6) Assessing HRQoL in pediatrics using PedsQL questionnaire.

\begin{tabular}{||l|l|l|l||}
\hline Variables & Deferoxamine & Deferasirox & p-value \\
\hline Number & 48 & 52 & - \\
\hline Physical functioning & $49.0 \pm 16.8$ & $62.1 \pm 20.0$ & $\mathbf{0 . 0 0 1}$ \\
\hline $\begin{array}{l}\text { Psychosocial health } \\
\text { summary }\end{array}$ & $67.4 \pm 13.3$ & $66.7 \pm 16.9$ & 0.820 \\
\hline Emotional functioning & $53.9 \pm 23.5$ & $58.1 \pm 24.4$ & 0.383 \\
\hline Social functioning & $79.8 \pm 15.4$ & $75.4 \pm 21.7$ & 0.240 \\
\hline School functioning & $69.3 \pm 21.8$ & $68.8 \pm 22.0$ & 0.918 \\
\hline Total summary score & $59.7 \pm 12.5$ & $64.8 \pm 16.7$ & 0.083 \\
\hline
\end{tabular}

\section{Predictorcs of QoL in pediatric patients}

Age and serum ferritin, are correlated inversely with QoL while the educational level is correlated directly with QoL in univariate analysis, but they lose the correlation in multivariate analysis.

Table (7) Predictors of QoL for pediatric patients

\begin{tabular}{||l|l|l|l|l||}
\hline & Univariate & Multivariate \\
\hline Age & $\mathrm{r}$ & $\mathrm{p}$-value & $\mathrm{r}$ & $\mathrm{p}$-value \\
\hline Treatment (Deferasirox) & -0.290 & $0.003[\mathrm{~S}]$. & -0.047 & 0.650 \\
\hline Education level & 0.179 & 0.075 & -0.078 & 0.456 \\
\hline Frequency of attendance & 0.234 & $0.019[\mathrm{~S}]$. & 0.192 & 0.063 \\
\hline Thalassemic facies & -0.030 & 0.771 & - & - \\
\hline Splenectomy & -0.149 & 0.139 & - & - \\
\hline Ferritin & -0.114 & 0.257 & - & - \\
\hline $\mathrm{R}^{2}=0.466$ & -0.223 & $0.026[\mathrm{~S}]$. & -0.123 & 0.237 \\
\hline
\end{tabular}

\section{Discussion}

The onset at which disease was diagnosed was ranging from 4-22 months table (1). This range was consistent with a study conducted in Basrah governorate by Abdul-Zahra et al. ${ }^{(24)}$ in which the range at disease onset in their study was 4-18 months. Patients usually presented with severe microcytic/ hypochromic anemia with mild jaundice and hepatosplenomegaly, with hematological features of reduced $\mathrm{Hb}$ levels $(<7 \mathrm{~g} / \mathrm{dL})$ and very low $\mathrm{MCH}(<20 \mathrm{Pg})$ with erythrocyte morphological changes on blood smear ${ }^{(25)}$. The frequency of the patients' attendance was consistent with Ansari et al. (14) and ranging from 10-20 days. This depends on the transfusion needs of each individual in order to maintain a hemoglobin level between 9 and 10 g/dLto promote normal growth, normal physical activity, and to inhibit ineffective erythropoiesis ${ }^{(26)}$. The complications associated with $\beta$-TM are age related; adults are associated with significantly increased complications as compared to pediatrics, table (2) and figure (1). Despite the new advances in thalassemia management, thalassemic patients in developing countries do not receive satisfactory treatment. For chronic conditions as thalassemia not only survival is the subject of concern but also QoL of the patient. QoL in patients with $\beta$-TM is affected by disease complication as they obviously associated with dramatic psychological effects, hopelessness, emotional burden and social integration problems ${ }^{(15,27)}$.

In the present study, WHOQOL-BREF tool
(Arabic version) was used for the assessment of HRQoL in adult thalassemics. Despite the difference between the present study and other previous studies in questionnaires, methodologies, and number of patients used, our scores of QoL domains in both DFO and DFX groups were comparable to many other studies $(19,27,28)$ and showed severe impairment in all aspects of QoL, table (4).

Adult patients using DFX show better QoL than patients' using DFO, and this was consistent with many studies $(19,29,30)$. Table (5) shows a significant direct relationship between DFX and all QoL domains; this was explained by Goulas et al. (30) who reported that patients are more adherent to the oral iron chelator which is considered an important parameter for treatment success.

Age in adults has a non-significant correlation with QoL which was in agreement with Ali et al. (28) who attributed the non-significant correlation to the fact that adult patients are aware enough to adjust and cope with their disease. We also found that adult patients have slightly lower QoL in comparison with their younger counterparts, this may be attributed to the fact that as age increases the severity of the disease and complications also increase which was consistent with Ajijet al. ${ }^{(31)}$.

Educational level in adults is considered a powerful parameter that is correlated with all aspects of QoL. It is clear from table (5) that education has a significant direct correlation with all QoL domains, which was found to agree with Ansari et 
$a l .^{(19)}$ and Gin et al. ${ }^{(20)}$ in which patients with higher educational levels have better QoL.

Thalassemic facies and poor body image in adult thalassemia patients have a negative impact on QoL domains. Since Iraq lacks supportive strategies as in developed countries, most of our patients suffering from negative feelings and poor selfesteem which affect their HRQoL, This was consistent with Khuranaet al. ${ }^{(32)}$

In the present study, there was no impact of frequency of blood transfusion on adults' HRQoL which was in contrast to Khuranaet al. ${ }^{(32)}$ who explained that patients with more frequent hospital visits for blood transfusion have worse QoL than those with less frequent visits. There was no significant effect of splenectomy on adults' QoL domains which was in agreement with Mohammed et al. ${ }^{(33)}$

Serum ferritin (SF) was found to have a negative impact on some of adults' domains mainly psychological and environmental domains, which was consistent with Ajijet al. ${ }^{(31)}$. In the present study, it is noticed that SF levels are considered a big concern to the patient and their families.

Once again, few studies were performed to assess HRQoL in Iraqi pediatrics. Thus, emphasizing the importance of maintaining QoL in pediatrics; since thalassemia have a negative impact on the physical functioning of the children and adolescents. It can also affect their social relationships and their mental health resulting in reduced school performance and impaired overall QoL. The Arabic version of the PedsQL 4.0 ${ }^{\mathrm{TM}}$ tool was used to assess the QoL in pediatrics.

Many studies have used the PedsQL $4.0^{\mathrm{TM}}$ questionnaire to evaluate $\mathrm{HRQ}$ oL in pediatrics, and all of them found that QoL scores are lower than control ${ }^{(16,34,35)}$. A normal child should have scores equal or close to $100^{(36)}$. Although no difference was found in the total summary score between pediatrics on DFO and pediatrics on DFX, table (6); the physical functioning score was significantly lower in the DFO patients this was in accordance to Elalfyet al. ${ }^{(37)}$ which could be attributed to patients non-compliance on DFO. Elalfy also reported that DFO treatment in pediatrics is quite difficult since it involves using the subcutaneous injection for $8 \mathrm{hrs}$ per day, five days per week ${ }^{(37)}$.

In contrast to adult patients, advancing in the age in pediatrics has a negative impact on QoL in univariate analysis, but it loses its correlation in multivariate analysis as shown in table (7), This was in agreement with Dhiraret $a l^{(36)}$ and Thavorncharoensapet al. ${ }^{(40)}$ because pediatrics with recent onset of the disease have less iron overload and complications this explains the higher QoL scores in pediatrics in comparison to adults.

Type of iron chelation in contrast to adult patients has no significant impact on pediatrics' QoL which was in agreement with Kaheni et al. ${ }^{(39)}$.
Pediatric educational status as in adults has a significant impact on QoL general score which was in agreement with Kaheniet al. ${ }^{(39)}$ and Hamid et $a l{ }^{(40)}$. Educated parents are keen on the education of their children, in turn; they have more information about the nature of the disease.

As in adults, the frequency of attendance for blood transfusion in pediatrics has no impact on HRQoL which was in agreement with Thavorncharoensapet al. ${ }^{(38)}$

In contrast to adults, the effect of thalassemic facies on QoL in pediatric was insignificant, the same finding was reported by Kaheniet al. ${ }^{(39)}$. The insignificant findings may be attributed to small sample size. Splenectomy effect on pediatrics was insignificant (the same findings in adults) this was in agreement with Kaheniet al. ${ }^{(39)}$ and Chordiyaet al. (41)

Serum ferritin (a dependent variable) has a negative impact on pediatrics' HRQoL (as in adults) and their parents, This was in agreement with Boonchooduanget al. $^{(16)}$.

Patients are fully aware of SF levels; as it goes up the more impairment in their QoL scores ensues, this was in agreement with Tuysuzet al. ${ }^{(42)}$ even though SF levels in their study was lower than our pediatrics levels.

\section{Conclusion}

$\beta$-TM impairs QoL significantly. Factors that should be considered to improve QoL among thalassemia major are better managing iron overload and side effects associated with ICTs, and prevention of complications. Education, financial support, and supportive strategies are major measures to improve overall QoL in $\beta$-TM.

\section{Acknowledgements}

Special thanks to Al-Karama teaching hospital and hereditary blood disorders employees. We are appreciative to Dr. Sarmad S. Hussein for his help in accomplishing the research.

\section{References}

1. Cossio MLT, Giesen LF, Araya G, et al. Hoffbrands Essential Haematology. 7th ed. Hoffbrand AV, Moss PAH, editors. Vol. XXXIII, Wiley Blackwell. John Wiley \& Sons Ltd.; 2016. 73-85 p.

2. Marengo-Rowe AJ. The thalassemias and related disorders. Proceedings (Baylor University Medical Center). 2007;20(1):27-31.

3. Jha R, Jha S. Beta thalassemia - a review. Journal of Pathology of Nepal. 2014;4:663-71.

4. Kadhim KA, Baldawi KH, Lami FH. Prevalence, Incidence, Trend, and Complications of Thalassemia in Iraq. Hemoglobin. 2017;41(3):164-8.

5. Higgs DR, Engel JD, Stamatoyannopoulos G. Thalassaemia. In: The Lancet. 2012. p. 373-83.

6. Salvatori F, Gambari R. Strategies for the adult haemoglobin (HbA) production in $\beta 0$ - 
thalassemia patients. Università degli Studi di Ferrara; 2008.

7. Danjou F, Anni F, Galanello R. Betathalassemia: From genotype to phenotype. Haematologica. 2011;96(11):1573-5.

8. Makroo RN, Bhatia A. Provision of ideal transfusion support - The essence of thalassemia care. Apollo Medicine. 2014;11(3):184-90.

9. Poggiali E, Cassinerio E, Zanaboni L, et al. An update on iron chelation therapy. Blood Transfusion. 2012;10(4):411-22.

10. Porter JB, Shah FT. Iron overload in thalassemia and related conditions: Therapeutic goals and assessment of response to chelation therapies. Hematology/Oncology Clinics of North America. 2010;24(6):1109-30.

11. Porter JB, Evangeli M, El-Beshlawy A. The challenges of adherence and persistence with iron chelation therapy. International Journal of Hematology. 2011;94(5):453-60.

12. Hershko C. Pathogenesis and management of iron toxicity in thalassemia. Annals of the New York Academy of Sciences. 2010;1202:1-9.

13. Ajij M, Pemde HK, Chandra J. Quality of Life of Adolescents With Transfusion-dependent Thalassemia and Their Siblings: A Crosssectional Study. Journal of Pediatric Hematology/Oncology. 2015;37(3):200-3.

14. Gupta M, Jindal R. Quality of life in patients with thalassemia major. International Journal of Science and Research. 2016;5(5):41-2.

15. Caocci G, Efficace F, Ciotti F, et al. Health related quality of life in Middle Eastern children with beta-thalassemia. BMC Blood Disorders. 2012;12(1):6.

16. 16. Boonchooduang $\mathrm{N}$, Louthrenoo $\mathrm{O}$, Choeyprasert W, et al. Health-Related Quality of Life in Adolescents with Thalassemia. Pediatric Hematology and Oncology. 2015;32(5):341-8.

17. Panepinto JA. Health-related quality of life in patients with hemoglobinopathies. Hematology. 2012;2012(1):284-9.

18. Ohaeri JU, Awadalla AW. The reliability and validity of the short version of the WHO Quality of Life Instrument in an Arab general population. Annals of Saudi Medicine. 2009;29(2):98-104.

19. Ansari S, Baghersalimi A, Azarkeivan A, et al. Quality of life in patients with thalassemia major. Iranian journal of pediatric hematology and oncology. 2014;4(2):57-63.

20. Gan GG, Sathar J. Factors Affecting Quality of Life in Adult Patients with Thalassaemia Major and Intermedia. Annals Academy of Medicine. 2016;45(11):520-3.

21. The WHOQOL Group. Whoqol-Bref: Introduction, Administration, Scoring and Generic Version of the Assessment. Programme on Mental Health. 1996;

22. Mevada ST, Al Saadoon M, Zachariah M, et al. Impact of burden of thalassemia major on health- related quality of life in Omani children. Journal of Pediatric Hematology/Oncology. 2016;38(5):384-8.

23. Arabiat D, Elliott B, Draper P, et al. Crosscultural Validation of the Pediatric Quality of Life Inventory ${ }^{\mathrm{TM}} 4.0$ (PedsQL $^{\mathrm{TM}}$ ) generic core scale into Arabic Language. Scandinavian Journal of Caring Sciences. 2011;25(4):828-33.

24. Abdul-zahra H, Hassan MK, Ahmed B. Healthrelated Quality of Life in Children and Adolescents With $\beta$-Thalassemia Major on Different Iron Chelators in Basra, Iraq. Journal of Pediatric Hematology/Oncology. 2016;38(7):503-11.

25. Brancaleoni V, Di Pierro E, Motta I, et al. Laboratory diagnosis of thalassemia. International Journal of Laboratory Hematology. 2016;38:32-40.

26. Langhi D, Ubiali EMA, Marques JFC, et al. Guidelines on Beta-thalassemia major - regular blood transfusion therapy. Brazilian Journal of Hematology and Hemotherapy. 2016;38(4):341-5.

27. Alzahrani RA, Almutairi OM, Alghoraibi MS, et al. Quality of life in transfusion-dependent thalassemia patients. Journal of Taibah University Medical Sciences. 2017;12(5):46570.

28. Ali SS, Tarawah AM, Al-Hawsawi ZM, et al. Comprehensive patient care improves quality of life in transfusion dependent patients with $\beta$ thalassemia. Saudi Medical Journal. 2015;36(5):575-9.

29. Seyedifar M, Dorkoosh FA, Hamidieh AA, et al. Health-related quality of life and health utility values in beta thalassemia major patients receiving different types of iron chelators in Iran. International Journal of Hematology-Oncology and Stem Cell Research. 2016;10(4):224-31.

30. Goulas V, Kourakli-Symeonidis A, Camoutsis C. Comparative effects of three iron chelation therapies on the quality of life of greek patients with homozygous transfusion-dependent Betathalassemia. ISRN hematology. 2012;2012.

31. Ajij M, Pemde HK, Chandra J. Quality of life of adolescents with transfusion-dependent thalassemia and their siblings: A cross-sectional study. Journal of Pediatric Hematology/Oncology. 2015;37(3):200-3.

32. Khurana A, Katyal S, Marwaha RK. Psychosocial burden in thalassemia. Indian journal of pediatrics. 2006;73(10):877-80.

33. Mohammed MA, Al-Nuaimi YE. Better Understanding of Health Related Quality of Life in Thalassemia Patients Treated by Iron Chelation Therapy in the United Arab Emirates. University of Oslo; 2015.

34. Soliman AT, Yassin MA, De Sanctis V. Final adult height and endocrine complications in young adults with $\beta$-thalassemia major (TM) 
who received oral iron chelation (OIC) in comparison with those who did not use OIC. Acta bio-medica : Atenei Parmensis. 2018;89(2S):27-32.

35. Nur N, Kibik A, Kilic E, et al. Health-related Quality of Life and Associated Factors Among Undergraduate University Students. Oman medical journal. 2017;32(4):329-34.

36. Dhirar N, Khandekar J, Bachani D, et al. Thalassemia Major: how do we improve quality of life? SpringerPlus. 2016;5(1):0-5.

37. Labib J, RezkAllah H, Elalfy M, et al. Quality of life of Egyptian b-thalassemia major children and adolescents. The Egyptian Journal of Haematology. 2014;39(4):222.

38. Thavorncharoensap M, Torcharus K, Nuchprayoon I, et al. Factors affecting healthrelated quality of life in Thai children with thalassemia. BMC Hematology. 2010;10(1):1.
39. Kaheni S, Yaghobian M, Sharefzadah GH, et al. Quality of life in children with beta-thalassemia major at center for special diseases. Iranian journal of pediatric hematology and oncology. 2013;3(3):108-13.

40. Asyikeen WAWN, Azrin AHS, Zulkifli MM, et al. Factors Affecting Health-Related Quality Of Life Among Paediatric Patients With Thalassemia: A Review Of Literature. Malaysian Journal of Pediatrics and Child Health Online Early. 2017;

41. Chordiya K, Katewa V, Sharma P, et al. Quality of Life (QoL) and the Factors Affecting it in Transfusion-dependent Thalassemic Children. Indian Journal of Pediatrics. 2018;1-6.

42. Tuysuz G, Tayfun F. Health-related quality of life and its predictors among transfusion dependent thalassemia patients. J Pediatr Hematol Oncol. 2017;00(00):1-5. 